\title{
Effects of Sublethal Doses of Methyl Benzoate on the Life History Traits and Acetylcholinesterase (AChE) Activity of Aphis gossypii
}

\author{
Md Munir Mostafiz ${ }^{1}\left({ }^{10}\right.$, Md Badrul Alam $^{2,3}{ }^{\circledR}$, Hsin Chi ${ }^{4}$, Errol Hassan ${ }^{5}$, Jae-Kyoung Shim ${ }^{1,6}$ \\ and Kyeong-Yeoll Lee $1,7,8, * \mathbb{D}$ \\ 1 Division of Applied Biosciences, College of Agriculture and Life Sciences, Kyungpook National University, \\ Daegu 41566, Korea; munirmostafiz12@gmail.com (M.M.M.); astelia@naver.com (J.-K.S.) \\ 2 Department of Food Science and Biotechnology, Graduate School, Kyungpook National University, \\ Daegu 41566, Korea; mbalam@knu.ac.kr \\ 3 Food and Bio-Industry Research Institute, Inner Beauty/Antiaging Center, Kyungpook National University, \\ Daegu 41566, Korea \\ 4 Department of Entomology, National Chung Hsing University, Taichung 402, Taiwan; \\ hsinchi@dragon.nchu.edu.tw \\ 5 School of Agriculture and Food Sciences, The University of Queensland Gatton, \\ Gatton, QLD 4343, Australia; e.hassan@uq.edu.au \\ 6 Institute of Agricultural Science and Technology, Kyungpook National University, Daegu 41566, Korea \\ 7 Sustainable Agriculture Research Center, Kyungpook National University, Gunwi 39061, Korea \\ 8 Research Institute for Dok-do and Ulleung-do Island, Kyungpook National University, Daegu 41566, Korea \\ * Correspondence: leeky@knu.ac.kr; Tel.: +82-53-950-5759 or +82-10-7164-5701
}

Received: 1 August 2020; Accepted: 31 August 2020; Published: 2 September 2020

check for updates

\begin{abstract}
Safer alternatives to synthetic pesticides are essential for sustainable agriculture. Methyl benzoate (MB) is a volatile essential oil found in several plants. Recent reports of the toxicity of MB to arthropod pests suggest that MB may be a useful alternative insecticide. The present study assessed the effects of a sublethal concentration of $\mathrm{MB}\left(\mathrm{LC}_{30}, 0.22 \%\right)$ on the life history and reproductive characteristics of the cotton aphid, Aphis gossypii Glover, in both a treated parental generation $\left(\mathrm{F}_{0}\right)$ and untreated progeny $\left(\mathrm{F}_{1}\right)$. MB treatment significantly decreased longevity and fecundity in both the $F_{0}$ and $F_{1}$ generations, and prolonged the developmental duration of each immature instar of the $\mathrm{F}_{1}$ generations, compared with controls. The intrinsic rate of increase $(r)$, finite rate of increase $(\lambda)$, and net reproductive rate $\left(R_{0}\right)$ of the $\mathrm{F}_{1}$ generation were significantly reduced, compared to controls. The mode of action of $\mathrm{MB}$ is not known, but in aphids treated with $\mathrm{LC}_{30} \mathrm{MB}$, the activity of the enzyme acetylcholinesterase (AChE) decreased by more than $65 \%$, compared with untreated controls. AChE activity was rapidly inhibited within $1 \mathrm{~h}$, and remained inhibited for $6 \mathrm{~h}$ after in vivo exposure to MB. Moreover, molecular docking analysis revealed that MB had a strong affinity with the catalytic site of $\mathrm{AChE}$, with a binding energy value of $-6.2 \mathrm{kcal} / \mathrm{mole}$. Our results suggest that $\mathrm{MB}$ targets $\mathrm{AChE}$, and that a sublethal dose of $\mathrm{MB}$ can have adverse transgenerational effects on cotton aphids.
\end{abstract}

Keywords: natural pesticide; sublethal effects; two-sex life table; population parameters; enzyme activity; molecular target

\section{Introduction}

The cotton aphid, Aphis gossypii Glover (Hemiptera: Aphididae), is a common agricultural insect pest that attacks crops worldwide [1]. The cotton aphid damages plants directly by consuming 
sap, and indirectly by transmitting viral diseases and contaminating plants with honeydew [2,3]. Cotton aphids are carriers of at least 76 viral diseases, threatening 900 known host plants [1]. Synthetic chemical insecticides are the most common current control methods for cotton aphids $[4,5]$. However, cotton aphids have developed resistance to many pesticides, due to frequent use [6-8]. In addition, the side effects of synthetic pesticide use include environmental hazards, residue problems, and negative impacts on natural enemies, reiterating the importance of finding alternative control methods.

Pesticides cause insect pest mortality when a lethal dose is applied; however, sublethal effects should also be considered to gain a comprehensive understanding of the effect of insecticides. Insects are often exposed to sublethal concentrations of pesticides because the chemicals naturally degrade following application to crops [9]. Sublethal pesticide doses do not kill the whole pest population, but may result in behavioral or physiological effects, such as altering the development, longevity, and reproduction of individual insects [10-12]. Additionally, certain effects of sublethal insecticide exposure in one insect generation can be transferred to the unexposed offspring of the next generation $[13,14]$. Most research investigating the transgenerational effects of insecticides has focused on egg development and hatching success [13-16]. Apart from these short-term variables, the transgenerational effects of insecticides on longer-term life-cycle traits require further research [14].

Life table analysis is a key method for the study of insect population dynamics [17]. In this study, we evaluate the effects of a sublethal concentration of methyl benzoate (MB) on selected biological parameters of cotton aphids. We compare the effects of $\mathrm{MB}$ on an exposed parental population with their unexposed offspring generation. Although the cotton aphid mostly reproduces parthenogenetically, the age-stage, two-sex life table approach takes into consideration different growth rates between individuals, as well as stage differentiation.

Recently, MB was demonstrated to be an effective insecticide against several insect pests [18]. $\mathrm{MB}$ is a naturally occurring compound found in various plant species [19] that degrades slowly in the atmosphere [20]. Our recently published results show that MB was acutely toxic to several arthropods, namely Bemisia tabaci Gennadius (Hemiptera: Aleyrodidae), Tetranychus urticae Koch (Acari: Tetranychidae), and A. gossypii. However, MB was much less toxic to the non-target organisms, Chrysoperla carnea Stephens (Neuroptera: Chrysopidae) and Nesidiocoris tenuis Reuter (Hemiptera: Miridae) [21-24]. Based on the above results, MB has potential as a safe, or "green", pesticide that can be applied in integrated pest management.

Agricultural insecticides control pests through several "modes of action". The majority of insecticides affect the nervous system, typically by inhibiting acetylcholinesterase (AChE), an important enzyme that catalyzes the breakdown of the neurotransmitter acetylcholine, resulting in the termination of nerve impulse transmissions [25]. The AChE system is targeted by organophosphate (OP) and carbamate insecticides [26,27]. To date, no literature has been published on the effects of MB on the AChE system in cotton aphids, nor on possible transgenerational effects of MB. Thus, we investigated the mechanism of action of MB and evaluated the effects of a sublethal dose of MB on aphid growth and reproductive traits, while also considering the transgenerational effects. An investigation of AChE activity inhibition by $\mathrm{MB}$ and a molecular docking study were undertaken to evaluate the possibility of molecular interaction between $\mathrm{MB}$ and $\mathrm{AChE}$ in the cotton aphid. The results of our research provide a benchmark for understanding the efficacy of MB for cotton aphid control, as well as important aspects of the physiological and biochemical responses of cotton aphids to MB treatment.

\section{Materials and Methods}

\subsection{Insects and Reagents}

A laboratory cotton aphid colony was sourced from the Rural Development Administration (RDA), Jeonju, Korea. The colony was established on cucumber plants (Cucumis sativus L.) in a laboratory 
maintained at $25 \pm 1{ }^{\circ} \mathrm{C}$ and $60 \pm 10 \%$ relative humidity $(\mathrm{RH})$, with a $16: 8 \mathrm{~h}$ light/dark photoperiod. The colony has been maintained without any exposure to insecticides since 2017.

Commercially available MB (99\% purity) and emulsifiers Tween 20 and Tween 80 were purchased from Sigma-Aldrich (St. Louis, MO, USA). The sublethal dose of MB was the $\mathrm{LC}_{30}$ concentration $(0.22 \%)$ determined in our previous study [22]. The $0.22 \% \mathrm{MB}$ solution and the control solution were prepared in distilled water, according to our published procedure [21].

\subsection{Sublethal Effects of Methyl Benzoate on the Cotton Aphid F0 Generation}

The toxicity of MB against cotton aphid adults ( $\leq 24$-h-old) was evaluated, according to the procedure published by Cui et al. [8]. Cucumber leaf discs (20 $\mathrm{mm}$ in diameter) were dipped into the control or $\mathrm{MB}$ solution $\left(\mathrm{LC}_{30}\right)$ for $5 \mathrm{~s}$, then allowed to air dry for $\sim 30 \mathrm{~min}$. After drying, the treated leaf discs were placed into Petri dishes $(5 \mathrm{~cm} \mathrm{D} \times 1.5 \mathrm{~cm} \mathrm{H})$ containing $1 \%$ agar (Junsei Chemical Co., Ltd., Tokyo, Japan), with the leaf underside resting on the agar bed. The agar provided moisture to prevent desiccation of the leaf discs. Ventilation was provided in the Petri dishes by cutting a $2 \mathrm{~cm}$ diameter hole in each lid and covering the hole with nylon mesh. For each treatment, including controls, 75 apterous adult aphids were used. Mortality data were collected $24 \mathrm{~h}$ after the aphids were placed in the treatments. Any surviving aphids were transferred from treated leaves onto fresh untreated leaf discs using a camel hair brush. The untreated leaf discs were replaced every $3 \mathrm{~d}$ and mortality data were collected every $24 \mathrm{~h}$ until all of the remaining aphids were dead. These bioassays were conducted under laboratory conditions at $25 \pm 1{ }^{\circ} \mathrm{C}, 60 \pm 10 \% \mathrm{RH}$, and $16: 8 \mathrm{~h}$ light/dark cycle.

\subsection{Transgenerational Effects of Methyl Benzoate on the Cotton Aphid F1 Generation}

Newly born nymphs from the MB-treated $\mathrm{F}_{0}$ female adults were collected within $24 \mathrm{~h}$ and placed individually on untreated cucumber leaf discs in Petri dishes (as described in Section 2.2) to observe the transgenerational effects of MB. A total of 75 newborn $F_{1}$ nymphs were collected from each treatment (MB and control). Life-cycle characteristics, such as growth stage, fecundity, mortality, and longevity, were monitored daily. At the time of reproduction, the newly born nymphs were counted and transferred daily to fresh cucumber leaf discs until the reproducing adult died. Throughout the experiment, leaf discs were replaced every three days. All bioassays were conducted under the laboratory conditions described in the previous section.

\subsection{Preparation of Cotton Aphid Proteins}

Cotton aphid adults were treated with the $\mathrm{LC}_{30}$ dose of $\mathrm{MB}(0.22 \%)$. Aphids $(n=60)$ were exposed to $\mathrm{MB}$ for $0,1,3$, and $6 \mathrm{~h}$. After the exposures, the surviving aphids were collected and homogenized using $300 \mu \mathrm{L}$ of ice-cold phosphate buffer (PBS) (0.1 M, pH 7.4). Next, the homogenate material was centrifuged at $12,000 \mathrm{rpm}$ for $15 \mathrm{~min}$ at $4{ }^{\circ} \mathrm{C}$, and the supernatant was collected for the protein source. The protein concentration of the enzyme extract was evaluated using the Bradford method [28], with bovine serum albumin as the standard.

\subsection{Determination of Acetylcholinesterase Activity}

To measure AChE activity, acetylthiocholine iodide (ATChI, Sigma-Aldrich, St. Louis, MO, USA) was used as a substrate, following the methods described by Ellman et al. [29]. Next, $20 \mu \mathrm{L}$ of enzyme solution and $160 \mu \mathrm{L}$ of PBS (0.1 M, pH 7.4) were added to each well of a 96-well microplate (SPL, Pocheon, Korea). The mixtures were then incubated in a shaker for $15 \mathrm{~min}$ at $27^{\circ} \mathrm{C}$. After this procedure, $10 \mu \mathrm{L}$ of $75 \mathrm{mM}$ ATChI and $10 \mu \mathrm{L}$ of $0.1 \mathrm{M}$ dithionitrobenzoic acid (DTNB, Sigma-Aldrich, St. Louis, MO, USA) were added to each well. The absorbance was measured at $412 \mathrm{~nm}$ using a microplate reader (Victor3, PerkinElmer, Waltham, MA, USA). The change in absorbance was recorded every $30 \mathrm{~s}$ for $20 \mathrm{~min}$. All treatments were performed in triplicate. AChE activity was indicated as nmol of ATChI hydrolyzed/min/mg protein using an extinction coefficient of $1.36 \times 10^{4} \mathrm{M}^{-1} \mathrm{~cm}^{-1}$. 


\subsection{Molecular Docking Analysis of the Protein-Ligand}

The crystal structure of AChE (PDB ID 1QON) was obtained from the Protein Data Bank (PDB) (http://www.rcsb.org/pdb/home/home.do) [30]. To investigate whether MB has the ability to inhibit AChE, a molecular docking test was performed using AutoDock Vina. The protein structures were prepared using UCSF Chimera 1.13.1 (http://www.cgl.ucsf.edu/chimera) to remove all non-receptor atoms, including water, ions, and miscellaneous compounds. The ligand (MB) was prepared using ChemBio3D Ultra, version 12.0 (PerkinElmer, Waltham, MA, USA), then an MMFF94 energy minimization was performed. AutoDock Vina (The Scripps Research Institute, La Jolla, CA, USA) was used for the molecular docking simulations. The ligand was removed, and a site sphere was specified to define the active site of AChE. The center of the grid box was 33,67 , and $10 \AA$ on the $x, y$, and $\mathrm{z}$ axes, respectively, whereas the dimension $(\AA)$ was $16.02,15.98$, and 16.25 on the $\mathrm{x}, \mathrm{y}$, and $\mathrm{z}$ axes, respectively. The best confirmation with the lowest binding energy was selected. After the docking search was completed, it was visualized using a PyMOL Molecular Graphics System (version 1.7.4, Schrödinger, Inc., New York, NY, USA). The binding results were visualized as 3D and 2D diagrams using Discovery Studio Visualization, version 4.5 (Accelrys, Inc., San Diego, CA 92121, CA, USA) and LigPlot viewer (v.2.2, EMBL-EBI, Wellcome Genome Campus, Hinxton, Cambridgeshire, CB10 1SD, UK, http://www.ebi.ac.uk/thornton-srv/software/LIGPLOT), respectively.

\subsection{Statistical Analyses}

The population parameters, including intrinsic rate of increase $(r)$, finite rate of increase $(\lambda)$, net reproductive rate $\left(R_{0}\right)$, mean generation time $(T)$, age-stage specific survival rate $\left(s_{x j}\right)$, age-specific survival rate $\left(l_{x}\right)$, age-specific fecundity $\left(m_{x}\right)$, adult pre-reproductive period (APRP), total pre-reproductive period (TPRP), reproductive days $\left(R_{d}\right)$, age-specific maternity $\left(l_{x} m_{x}\right)$, age-stage life expectancy $\left(e_{x j}\right)$, and reproductive value $\left(v_{x j}\right)$, were calculated, according to the age-stage, two-sex life table theory [31-34] using TWOSEX-MSChart (ver. 2019.08.01; http://140.120.197.173/Ecology/ Download/Twosex-MSChart-exe-B100000.rar) [35]. The population parameter variances and standard errors were calculated using the 100,000 random resampling bootstrap technique [36]. The differences in population parameters between the control and MB treatment groups were measured using the paired bootstrap test, based on the confidence intervals implemented in TWOSEX-MSChart [34,35,37]. One-way ANOVA was used to assess differences in enzyme activity, followed by post-hoc Tukey HSD test $(p<0.05)$ (SAS version 9.4) [38]. SigmaPlot 12.5 [39] was used to create all graphs.

\section{Results}

\subsection{Sublethal Effects of Methyl Benzoate on the $F_{0}$ Generation}

Treatment of adult cotton aphids with $0.22 \% \mathrm{MB}$ using the leaf disc method significantly affected longevity and fecundity (Figure 1). Compared with the untreated control group, the adult longevity of $\mathrm{F}_{0}$ individuals treated with $\mathrm{MB}$ was significantly reduced from $20.37 \mathrm{~d}$ to $8.56 \mathrm{~d}(p<0.0001$; Figure 1$)$. Fecundity of the $\mathrm{F}_{0}$ generation also significantly decreased from 27.88 offspring/female in the control to 9.63 offspring/female in the MB treatment $(p<0.0001$; Figure 1). 
A

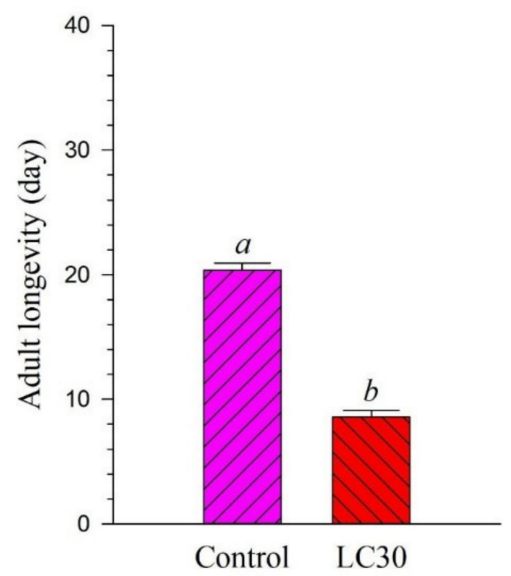

B

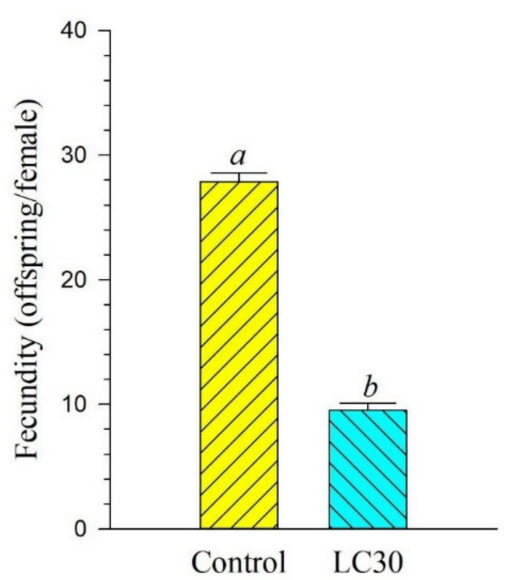

Figure 1. The initial $\left(\mathrm{F}_{0}\right)$ adult longevity $(\mathbf{A})$ and fecundity $(\mathbf{B})$ of Aphis gossypii treated with $\mathrm{LC}_{30}$ methyl benzoate (MB) or control for $24 \mathrm{~h}$. Bars labelled with different letters are significantly different based on a paired bootstrap test $(p<0.05)$. (A) and (B) indicates the adult survival and offspring/individual of A. gossypii, respectively.

\subsection{Sublethal Effects of Methyl Benzoate on the $F_{1}$ Generation}

The effects on the $F_{1}$ generation of treating the $F_{0}$ generation of aphids with $\mathrm{LC}_{30} \mathrm{MB}$ are presented in Table 1. Compared with the untreated control group, the mean longevity and fecundity of the $\mathrm{F}_{1}$ generation significantly decreased, due to the treatment of the parental generation with $\mathrm{LC}_{30}$ of $\mathrm{MB}$ $(p<0.0001)$. Furthermore, after exposing the $\mathrm{F}_{0}$ individuals to $\mathrm{MB}$, the growth period of each immature stage of the $\mathrm{F}_{1}$ generation significantly increased $(p<0.0001)$. This shows that $\mathrm{F}_{0} \mathrm{MB}$ treatment significantly increased the pre-adult duration $(p<0.0001)$, APRP $(p<0.0001)$, and TPRP $(p<0.0001)$ of the $F_{1}$ progeny, compared to the control. A significant difference in the number of reproductive days of the $\mathrm{F}_{1}$ generation was also observed between the MB and control treatment groups $(p<0.0001$; Table 1$)$.

Table 1. Transgenerational effects of methyl benzoate on developmental times, longevity, adult pre-reproductive period (APRP), total pre-reproductive period (TPRP), and mean fecundity of $\mathrm{F}_{1}$ progeny Aphis gossypii when parental individuals $\left(\mathrm{F}_{0}\right)$ were exposed to the sublethal concentration $\left(\mathrm{LC}_{30}\right)$ of methyl benzoate.

\begin{tabular}{|c|c|c|c|c|c|}
\hline \multirow{3}{*}{ Biological Parameters } & \multicolumn{4}{|c|}{ Developmental Time (Days) of F1 Progeny } & \multirow{3}{*}{$p$} \\
\hline & \multicolumn{2}{|c|}{ Control } & \multicolumn{2}{|c|}{ Methyl Benzoate $\left(\mathrm{LC}_{30}\right)$} & \\
\hline & $\mathbf{N}$ & Mean $\pm S E^{a, b}$ & $\mathbf{N}$ & Mean $\pm S E E^{a, b}$ & \\
\hline First instar (d) & 68 & $2.10 \pm 0.05 a$ & 67 & $2.31 \pm 0.06 \mathrm{~b}$ & 0.0108 \\
\hline Second instar $(\mathrm{d})$ & 66 & $1.55 \pm 0.06 a$ & 65 & $2.14 \pm 0.06 \mathrm{~b}$ & $<0.0001$ \\
\hline Third instar (d) & 66 & $1.41 \pm 0.06 \mathrm{a}$ & 65 & $2.15 \pm 0.07 b$ & $<0.0001$ \\
\hline Fourth instar $(\mathrm{d})$ & 65 & $1.14 \pm 0.04 \mathrm{a}$ & 65 & $2.05 \pm 0.06 b$ & $<0.0001$ \\
\hline Pre-adult (d) & 65 & $6.17 \pm 0.08 \mathrm{a}$ & 65 & $8.68 \pm 0.09 b$ & $<0.0001$ \\
\hline Pre-adult survival rate $\left(s_{a}\right)$ & 75 & $0.87 \pm 0.039 a$ & 75 & $0.87 \pm 0.039 a$ & 1.000 \\
\hline Adult longevity (d) & 65 & $23.94 \pm 0.45 a$ & 65 & $12.0 \pm 0.43 b$ & $<0.0001$ \\
\hline Total longevity (d) & 75 & $26.51 \pm 1.14 a$ & 75 & $18.21 \pm 0.82 b$ & $<0.0001$ \\
\hline $\operatorname{APRP}(d)$ & 65 & $0.08 \pm 0.04 a$ & 65 & $0.65 \pm 0.14 b$ & $<0.0001$ \\
\hline $\operatorname{TPRP}(\mathrm{d})$ & 65 & $6.25 \pm 0.08 a$ & 65 & $9.32 \pm 0.16 b$ & $<0.0001$ \\
\hline
\end{tabular}


Table 1. Cont.

\begin{tabular}{|c|c|c|c|c|c|}
\hline \multirow{3}{*}{ Biological Parameters } & \multicolumn{4}{|c|}{ Developmental Time (Days) of F1 Progeny } & \multirow{3}{*}{$p$} \\
\hline & \multicolumn{2}{|c|}{ Control } & \multicolumn{2}{|c|}{ Methyl Benzoate $\left(\mathrm{LC}_{30}\right)$} & \\
\hline & $\mathbf{N}$ & Mean $\pm \mathrm{SE}^{\mathrm{a}, \mathrm{b}}$ & $\mathbf{N}$ & Mean $\pm \mathrm{SE}^{\mathrm{a}, \mathrm{b}}$ & \\
\hline Reproductive days (d) & 65 & $18.55 \pm 0.31 \mathrm{a}$ & 65 & $8.69 \pm 0.2 b$ & $<0.0001$ \\
\hline Fecundity (offspring/individual) & 65 & $35.2 \pm 0.45 a$ & 65 & $13.49 \pm 0.26 b$ & $<0.0001$ \\
\hline
\end{tabular}

\subsection{Transgenerational Effects of Methyl Benzoate on Population Parameters}

The transgenerational effects of $\mathrm{MB}\left(\mathrm{LC}_{30}\right)$ on population parameters of the $\mathrm{F} 1$ generation were assessed using a life table-based bootstrap technique. Compared to the control group, the intrinsic rate of increase $(r)$, finite rate of increase $(\lambda)$, the net reproductive rate $\left(R_{0}\right)$, and gross reproductive rate (GRR) significantly decreased $(p<0.0001)$, while the mean generation time $(T)(13.71 \pm 0.24)$ significantly increased in the MB treatment group, compared with the control group (12.42 \pm 0.23$)$ $(p<0.0001$; Table 2).

Table 2. Transgenerational effects of methyl benzoate on population parameters of the $\mathrm{F}_{1}$ generation of Aphis gossypii.

\begin{tabular}{cccc}
\hline \multirow{2}{*}{ Population Parameter $^{\mathbf{a}}$} & \multicolumn{2}{c}{ Bootstrap (Mean $\pm \mathbf{S E}{ }^{\mathbf{b}, \mathbf{c}} \mathbf{c}$} & \multirow{2}{*}{$\boldsymbol{p}$} \\
\cline { 2 - 3 } & Control & $\mathbf{M B}\left(\mathbf{L C}_{\mathbf{3 0}}\right)$ & \\
\hline$r\left(\mathrm{~d}^{-1}\right)$ & $0.2752 \pm 0.0069 \mathrm{a}$ & $0.1793 \pm 0.0048 \mathrm{~b}$ & $<0.0001$ \\
\hline$\lambda\left(\mathrm{d}^{-1}\right)$ & $1.3169 \pm 0.0092 \mathrm{a}$ & $1.1964 \pm 0.0058 \mathrm{~b}$ & $<0.0001$ \\
\hline$R_{0}$ (offspring/individual) & $30.51 \pm 1.43 \mathrm{a}$ & $11.69 \pm 0.57 \mathrm{~b}$ & $<0.0001$ \\
\hline$T(\mathrm{~d})$ & $12.42 \pm 0.23 \mathrm{a}$ & $13.71 \pm 0.24 \mathrm{~b}$ & $<0.0001$ \\
\hline GRR (offspring/individual) & $44.83 \pm 1.63 \mathrm{a}$ & $21.92 \pm 1.51 \mathrm{~b}$ & $<0.0001$ \\
\hline
\end{tabular}

a $r$ : intrinsic rate of increase; $\lambda$ : finite rate of increase; $R_{0}$ : net reproductive rate; T: mean generation time (offspring/individual); GRR: gross reproduction rate; ${ }^{\mathrm{b}}$ standard errors (SE) were estimated using the bootstrap technique with 100,000 re-samplings; ${ }^{c}$ differences between two treatments were compared using a paired bootstrap test implemented in TWOSEX-MSChart. The means in the same rows followed by different lower-case letters indicate significant differences between treatments $(p<0.05)$.

\subsection{Transgenerational Effects of Methyl Benzoate on Age-Stage Specific Rate of Survival and Fecundity}

The age-stage specific rate of survival $\left(s_{x j}\right)$ is the probability that a newly-born individual will survive to age $x$ and stage $j$ (Figure 2). Due to variable growth rates between individuals, considerable overlaps were observed between the life stages in the control and MB treatment groups (Figure 2). The pre-adult survival rate $\left(s_{a}\right)$ was not significantly different between treatments (Table 1).

The age-survival rate $\left(l_{x}\right)$ provides a simplistic description of the rate of survival without considering the stage distinction (Figure 3). In this study, the $l_{x}$ curve of MB-treated groups significantly decreased from 16-days-old, while the $l_{x}$ in the control group dropped from 22-days-old (Figure 3). The $l_{x}$ value for $\mathrm{LC}_{30}$ treatment with $\mathrm{MB}$ declined earlier, compared to the control. Based on the curve $m_{x}$ (age-specific fecundity) the control group's maximum age-specific fecundity rate (2.2 offspring) occurred at the age of $7 \mathrm{~d}$. Additionally, the MB-treated group had peak fecundity at 14-days-old (1.51 offspring) (Figure 3). Based on both $l_{x}$ and $m_{x}$, the maximum net maternity $l_{x} m_{x}$ value of 1.93 offspring occurred in the control group at 7-days-old, while the $l_{x} m_{x} 1.31$ in the MB-treated groups occurred at 14-days-old (Figure 3). 


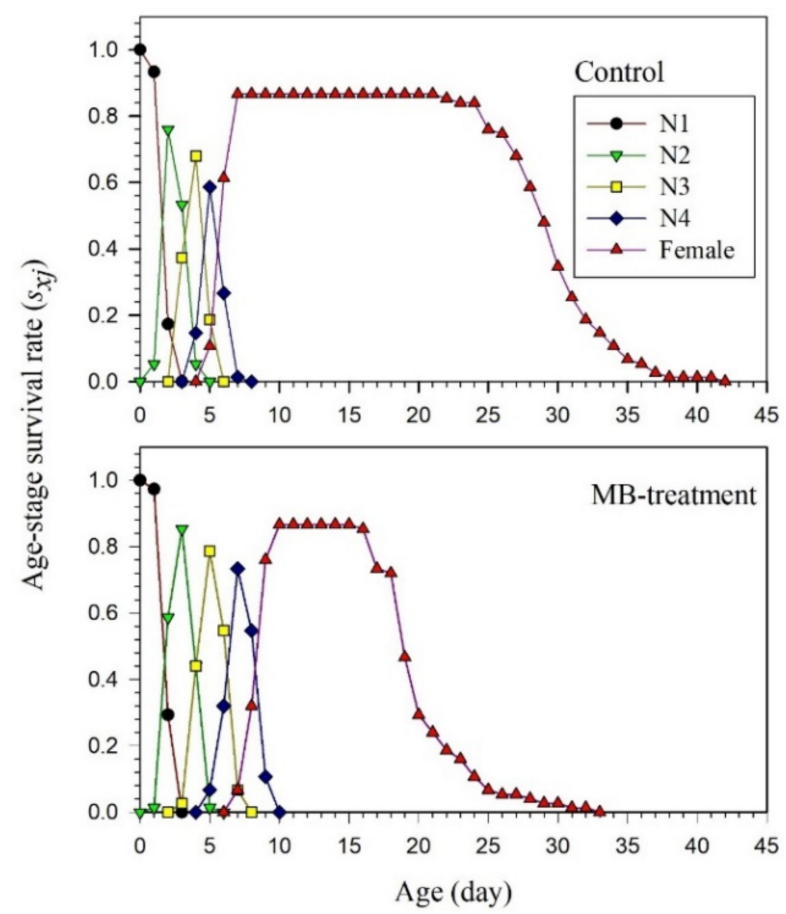

Figure 2. Age-stage-specific survival rates $\left(s_{x j}\right)$ for $\mathrm{F}_{1}$ Aphis gossypii descended from the parental generation $\left(\mathrm{F}_{0}\right)$ under control and MB-treatment $\left(\mathrm{LC}_{30}\right)$ condition. N1-N4 indicates the first to fourth instars of $A$. gossypii.
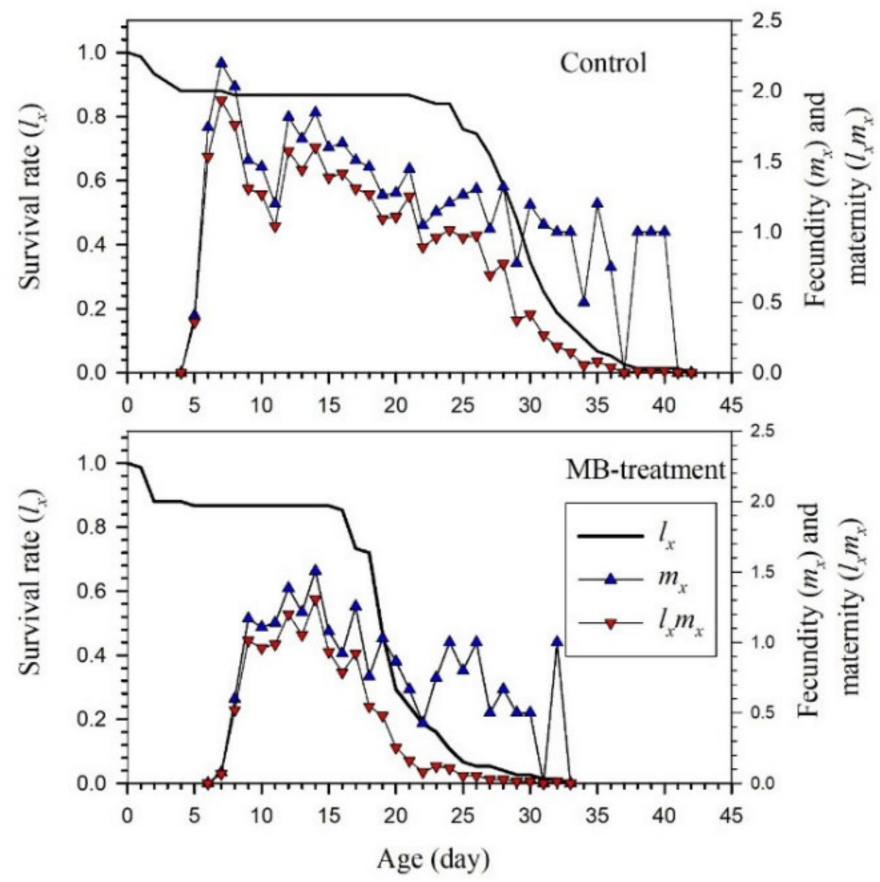

Figure 3. Age-specific survival rate $\left(I_{x}\right)$, age-specific fecundity of total population $\left(m_{x}\right)$, and age-specific maternity $\left(I_{x} m_{x}\right)$ for $\mathrm{F}_{1}$ Aphis gossypii descended from $\mathrm{F}_{0}$ exposed to $\mathrm{LC}_{30}$ methyl benzoate (MB).

The age-specific life expectancy $\left(e_{x j}\right)$ is the length of time that an individual of age $x$ and stage $j$ is expected to survive after age $x$ (Figure 4$)$. The life expectancy $\left(e_{x j}\right)$ of cotton aphids treated with MB was lower than the control group (Figure 4). 


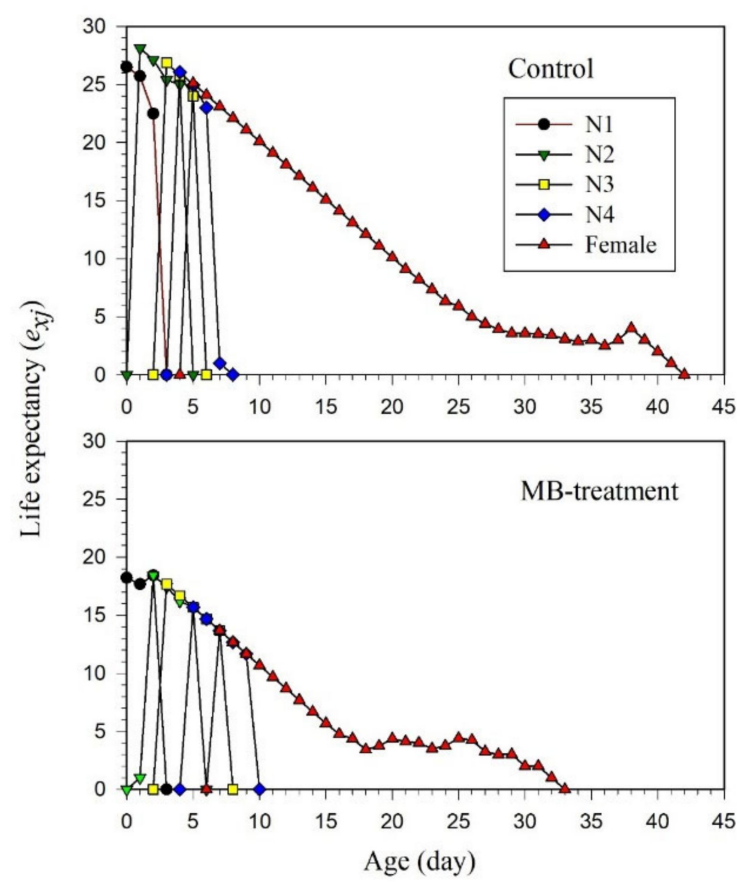

Figure 4. Age-stage-specific life expectancy $\left(e_{x j}\right)$ for $\mathrm{F}_{1}$ Aphis gossypii descended from $\mathrm{F}_{0}$ exposed to $\mathrm{LC}_{30}$ methyl benzoate.

In addition, the age-stage reproductive value $\left(v_{x j}\right)$ is an indicator of an individual's contribution to the future population at various ages and stages (Figure 5). In the MB-treated group, the maximum $v_{x j}$ value occurred significantly later (6.86/d at 8-days-old), compared to that in the control group (9.53/d at 5-days-old) (Figure 5).

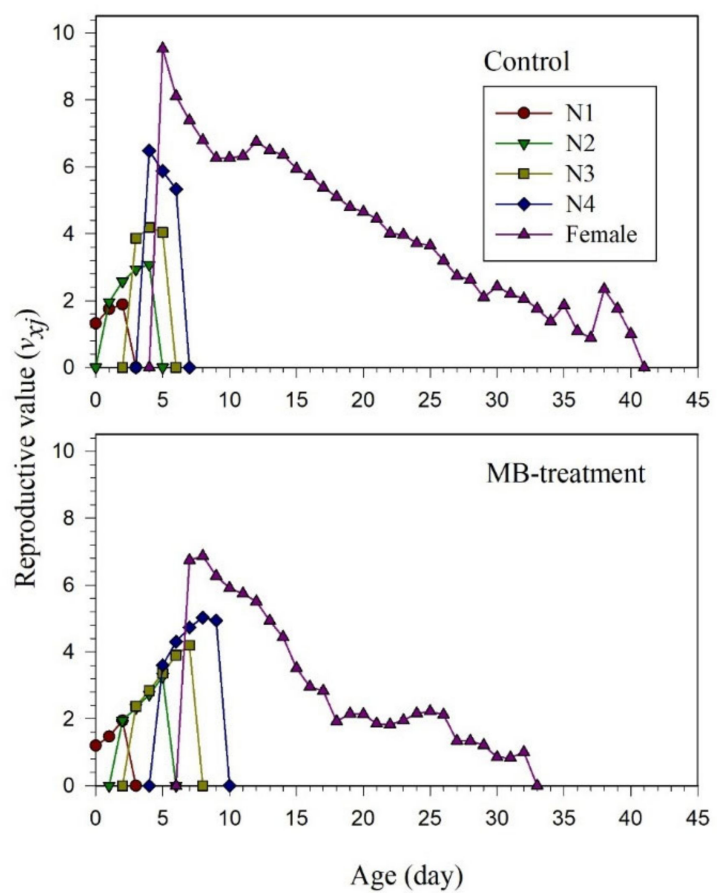

Figure 5. Age-stage reproductive value $\left(v_{x j}\right)$ of $\mathrm{F}_{1}$ Aphis gossypii descended from $\mathrm{F}_{0}$ exposed to $\mathrm{LC}_{30}$ methyl benzoate. 


\subsection{Effect of Methyl Benzoate on AChE Activity}

A direct correlation was observed between $\mathrm{AChE}$ activity and $\mathrm{MB}$ exposure period, thereby emphasizing the time-dependence of $\mathrm{MB}$ activity $(\mathrm{F}=7.99 ; \mathrm{df}=3,23 ; p<0.0001)$ (Figure 6$)$. In the time-course inhibition studies, AChE activity of A. gossypii was quickly inhibited by MB treatment, and remained inhibited following in vivo exposure (Figure 6). The high level of AChE inhibition by $1 \mathrm{~h}$ bioactivation occurred rapidly after exposure to MB. AChE activity decreased by more than $65 \%$ in MB-exposed aphids, compared to the control ( $p<0.0001$; Figure 6).

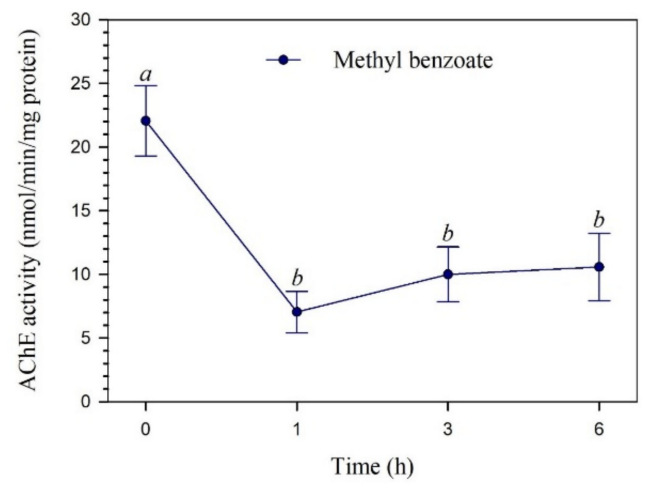

Figure 6. AChE activity of Aphis gossypii treated with $\mathrm{LC}_{30}(0.22 \%)$ methyl benzoate. The results are presented as mean \pm SE. Different letters above the bars indicate a significant difference between the times at $f<0.05$.

\subsection{Protein-Ligand Molecular Docking Analysis}

The molecular docking protocol must be validated before performing molecular docking studies. Therefore, to validate the protocols used in this analysis, the ligand crystallographic information was subjected to the development of docking until the spatial conformation was found by comparison with the original crystallographic structure of the AChE inhibitors (PDB ID 1QON). The validation was performed by retrieving the structure of an AChE inhibitor (I40) by calculating the root-mean-square deviation (RMSD) of $0.98 \AA$. The binding mode predicted using docking indicates that when the RMSD is less than $2.0 \AA$ regarding the crystallographic pose of a respective ligand, the validation is considered satisfactory $[40,41]$. The satisfactory results are illustrated in Figure $7 \mathrm{a}$.

The binding affinity between $\mathrm{MB}$ and the $\mathrm{AChE}$ protein was expressed as a binding energy value of $-6.2 \mathrm{kcal} / \mathrm{mol}$, while the actual ligand I40 (9-(3-iodobenzylamino)-1,2,3,4-tetrahydroacridine) binding with $A C h E$ had a value of $-12.5 \mathrm{kcal} / \mathrm{mol}$. As shown in Figure $7 \mathrm{~b}-\mathrm{d}$, the individually-observed interaction after MB docking was identical to I40 in the active site of AChE, found around the $\alpha$-helix between amino acid residues Tyr-370, Tyr-374, and Tyr-71, as well as the $\beta$-sheet with amino acid residue Trp-83. Quantitative data on residues, distances, and types between $\mathrm{MB}$ and the insect $\mathrm{AChE}$ are presented in Table S1 and Figure S1. 
A

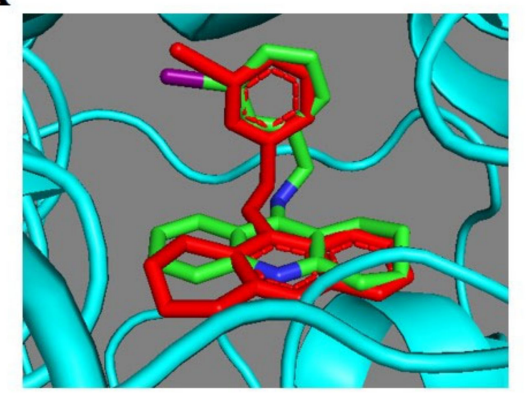

C

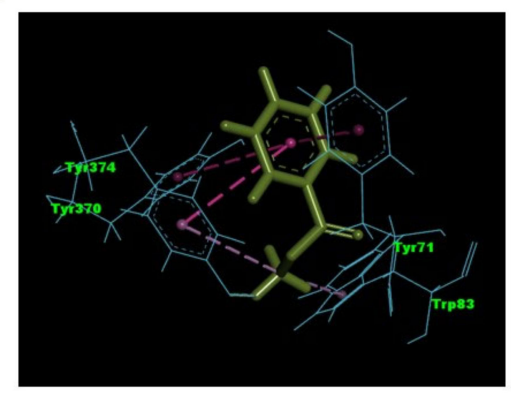

B

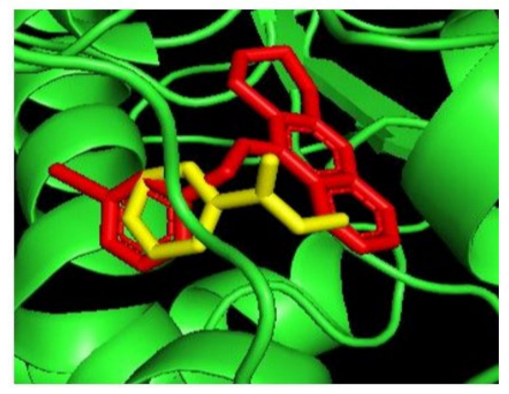

D

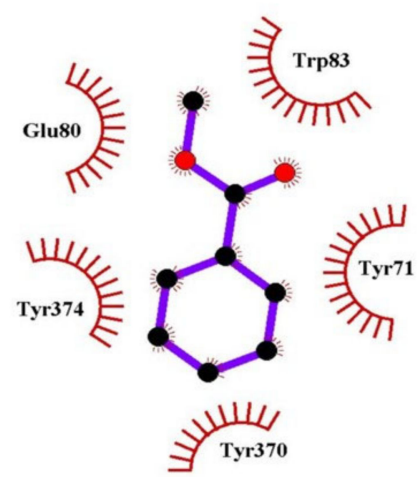

Figure 7. Molecular docking of MB with acetylcholinesterase (AChE); Protein Data Bank (PDB): $1 \mathrm{QON}$. Overlays of crystallographic ligand positions of I40 (in red), with the calculated pose (in green) (A); co-localization of the ligand I40 and MB (B); interactions of the active site of AChE of Drosophila melanogaster with the molecule $\mathrm{MB}$ in 3D (C) and 2D (D).

\section{Discussion}

Natural products can often provide a more environmentally-friendly approach to managing insect pests and plant diseases [42,43]. MB, which is a naturally occurring compound found in many plants, exhibits potent insecticidal activity against a variety of insect pests $[18,21-24,44]$. Therefore, MB could provide an alternative to synthetic insecticides for agricultural control of cotton aphids in the near future. However, the sublethal and transgenerational effects of $\mathrm{MB}$ on cotton aphids were previously unknown.

This study showed the effects of a sublethal dose of MB on the biological traits and AChE activity of the cotton aphid. We observed a significant decrease in adult survival and fecundity of $A$. gossypii directly exposed to the previously determined $\mathrm{LC}_{30}$ of MB. Similar effects were documented in an earlier study, in which the fecundity and longevity of $A$. gossypii significantly declined with exposure to sublethal doses of buprofezin [45]. Additionally, adult survival and fertility were significantly reduced when cotton aphids were treated with $\mathrm{LC}_{10}$ and $\mathrm{LC}_{40}$ cycloxaprid [46]. Aphid longevity and fertility in the aforementioned studies substantially decreased, but similar decreases were not observed in B. tabaci exposed to sublethal doses of imidacloprid [47]. Likewise, no decrease in longevity or fecundity was observed in Apolygus lucorum Meyer-Dür (Hemiptera: Miridae) exposed to a sublethal concentration of cycloxapride [16]. In addition, the reduced longevity and fecundity patterns observed in cotton aphids suggest a lack of hormesis, which is a common sublethal effect of insecticide exposure. Hormesis is a concentration-response biphasic process, which is normally characterized by stimulation at low concentrations and inhibition at high concentrations [48,49]. Insecticide-induced hormesis has been recorded in several insect species, for example, higher fecundity in Myzus persicae Sulzer (Hemiptera: Aphididae) subjected to low imidacloprid concentration [50] and Oligonychus ilicis McGregor (Acari: Tetranychidae) outbreaks caused by low doses of pyrethroid [51]. However, hormesis effects on the longevity and fecundity of the parental generation $\left(\mathrm{F}_{0}\right)$ of $A$. gossypii exposed to a sublethal concentration of MB were not observed in this study. 
Transgenerational effects of $\mathrm{MB}$ on cotton aphid progeny $\left(\mathrm{F}_{1}\right)$ were identified when the parental generation $\left(\mathrm{F}_{0}\right)$ was exposed to $\mathrm{LC}_{30} \mathrm{MB}$. The length of each nymphal stage and the pre-adult duration of the $\mathrm{F}_{1}$ progeny of $\mathrm{MB}$-exposed $\mathrm{F}_{0}$ were significantly extended. The delayed development rate we observed is comparable to earlier reports, such as the delayed development of Plutella xylostella $\mathrm{L}$. (Lepidoptera: Plutellidae) exposed to $\mathrm{LC}_{25}$ chlorantraniliprole [13]. Similarly, the duration of each developmental stage in Rhopalosiphum padi L. (Hemiptera: Aphididae) increased when exposed to sublethal concentrations of beta-cypermethrin or indoxacarb [52]. We found that the demographic parameters in the $F_{1}$ generation were substantially reduced, relative to the control, when the $F_{0}$ generation was subjected to $\mathrm{MB}$ exposure. Similar transgenerational effects on the offspring of white-backed planthopper, Sogatella furcifera Horváth (Hemiptera: Delphacidae) [53], and brown planthopper, Laodelphax striatellus Fallén (Hemiptera: Delphacidae) [54], were recorded after parental exposure to sublethal concentrations of buprofezin and sulfoxaflor. Although we have reported the GRR in this study, it is necessary to point out that because GRR excludes the survival rate, a higher GRR does not necessarily represent higher fitness; thus, it should be interpreted with caution.

Plotting the $s_{x j}, l_{x}, m_{x}, l_{x} m_{x}$, and $e_{x j}$ curves revealed the adverse effects of a sublethal dose of MB on cotton aphid population growth parameters. In the control treatment, the reproduction began on age 5 day, the peak of reproduction was on age 7 day, and the reproductive period extended from age 5 to 40 day. Consequently, the intrinsic rate of increase and finite rate of increase of the control treatment are significantly higher than that of MB treatment. Due to various physical and chemical processes, the pre-adult and mean generation time $(T)$ increased after exposure to MB. In a few other studies on A. gossypii, similar effects were reported at the demographic level $[12,55]$.

MB has been demonstrated as an excellent organic pesticide; however, the insecticidal mechanism of action of MB was not previously elucidated. Few studies have been conducted on the role of MB in human and animal subjects. A related compound methyl hydroxybenzoate has been shown to act on nervous conduction in the spinal root fibers of cats [56]. In rabbits, a sublethal dose of MB $(500 \mathrm{mg} / \mathrm{kg})$ increased blood cell counts but reduced cholinesterase activity; frequent application of high doses resulted in damage to the central nervous system [57]. AChE in the central nervous system of insects is an important target molecule for organophosphate and carbamate insecticides [58]. Our study showed that $A$. gossypii $\mathrm{AChE}$ activity decreased following treatment with $\mathrm{MB}$. This finding indicates that $\mathrm{MB}$ works directly or indirectly to suppress $\mathrm{AChE}$ activity, and therefore, $\mathrm{AChE}$ inhibition may be the mechanism for cotton aphid mortality. Furthermore, we simulated the molecular interaction between $\mathrm{MB}$ and $\mathrm{AChE}$ using a molecular docking program. Our results showed that MB docked at the catalytic site of the AChE molecule. Additionally, MB exhibited hydrophobic interactions with at least five AChE amino acids.

\section{Conclusions}

The results of this study demonstrate that the application of a sublethal concentration of MB adversely affects cotton aphid growth by extending the pre-adult period and suppressing the population growth of the progeny. In addition, this study is the first to explore the constructed atomistic AChE model for A. gossypii and its potential binding of MB through molecular docking analyses. Further research on the mode of action of MB on insects is recommended. Importantly, biopesticides such as MB could become key components of crop protection programs, reducing the use of synthetic and harmful chemical products. Adopting a more sustainable approach to pest management will benefit human health, the environment, and biodiversity.

Supplementary Materials: The following are available online at http://www.mdpi.com/2073-4395/10/9/1313/s1: Figure S1: The crystallographic structure of the Drosophila melanogaster acetylcholinesterase (AChE) complexed with tacrine derivative 9-(3-iodobenzylamino)-1,2,3,4-tetrahydroacridine (I40). The structure was downloaded from the Protein Data Bank (PDB), with PDB ID 1QON. Interactions between the active site of acetylcholinesterase of Drosophila melanogaster with the ligand I40; Table S1: Comparison of the molecular interaction of acetylcholinesterase with the reported inhibitor, I40 and MB. 
Author Contributions: Conceptualization: M.M.M., M.B.A., and K.-Y.L.; methodology: M.M.M. and M.B.A.; software: M.M.M., H.C., and M.B.A.; validation: M.M.M., H.C., and M.B.A.; formal analysis: M.M.M.; investigation: J.-K.S. and K.-Y.L.; resources: K.-Y.L.; data curation: H.C. and K.-Y.L.; writing-original draft preparation: M.M.M.; writing-review and editing: M.M.M., M.B.A., H.C., E.H., and K.-Y.L.; visualization: M.M.M., M.B.A., H.C., and K.-Y.L.; supervision: K.-Y.L.; project administration: K.-Y.L.; funding acquisition: K.-Y.L. All authors have read and agreed to the published version of the manuscript.

Funding: This research was supported by the Basic Science Research Program through the National Research Foundation of Korea (NRF), funded by the Ministry of Education (2016R1A6A1A05011910).

Acknowledgments: We give thanks to Jum-Rae Cho at Rural Development Administration (RDA), Jeonju, Korea, for providing the cotton aphid colony. We also give thanks to Penelope J. Gullan of the Research School of Biology at the Australian National University, Canberra, Australia, for her crucial advice for writing the manuscript and for assistance with English language idioms.

Conflicts of Interest: The authors declare that there are no conflict of interest for the current study.

\section{References}

1. Blackman, R.L.; Eastop, V.F. Aphids on the World's Crops: An. Identification and Information Guide, 2nd ed.; John Wiley \& Sons Ltd.: Chichester, UK, 2000.

2. Carletto, J.; Martin, T.; Vanlerberghe-Masutti, F.; Brévault, T. Insecticide resistance traits differ among and within host races in Aphis gossypii. Pest Manag. Sci. 2010, 66, 301-307. [CrossRef]

3. Ma, K.S.; Li, F.; Liu, Y.; Liang, P.Z.; Chen, X.W.; Gao, X.W. Identification of microRNAs and their response to the stress of plant allelochemicals in Aphis gossypii (Hemiptera: Aphididae). BMC Mol. Biol. 2017, 18, 5. [CrossRef]

4. Shrestha, R.B.; Parajulee, M.N. Potential cotton aphid, Aphis gossypii, population suppression by arthropod predators in upland cotton. Insect Sci. 2013, 20, 778-788. [CrossRef]

5. Wei, X.; Pan, Y.; Xin, X.; Zheng, C.; Gao, X.; Xi, J.; Shang, Q. Cross-resistance pattern and basis of resistance in a thiamethoxam-resistant strain of Aphis gossypii Glover. Pestic. Biochem. Physiol. 2017, 138, 91-96. [CrossRef] [PubMed]

6. Gore, J.; Cook, D.; Catchot, A.; Leonard, B.R.; Stewart, S.D.; Lorenz, G.; Kerns, D. Cotton aphid (Heteroptera: Aphididae) susceptibility to commercial and experimental insecticides in the southern United States. J. Econ. Entomol. 2013, 106, 1430-1439. [CrossRef] [PubMed]

7. Koo, H.N.; An, J.J.; Park, S.E.; Kim, J.I.; Kim, G.H. Regional susceptibilities to 12 insecticides of melon and cotton aphid, Aphis gossypii (Hemiptera: Aphididae) and a point mutation associated with imidacloprid resistance. Crop. Prot. 2014, 55, 91-97. [CrossRef]

8. Cui, L.; Qi, H.; Yang, D.; Yuan, H.; Rui, C. Cycloxaprid: A novel cis-nitromethylene neonicotinoid insecticide to control imidacloprid-resistant cotton aphid (Aphis gossypii). Pestic. Biochem. Physiol. 2016, 132, 96-101. [CrossRef]

9. Desneux, N.; Decourtye, A.; Delpuech, J.M. The sublethal effects of pesticides on beneficial arthropods. Annu. Rev. Entomol. 2007, 52, 81-106. [CrossRef]

10. Perveen, F.; Miyata, T. Effects of sublethal dose of chlorfluazuron on ovarian development and oogenesis in the common cutworm Spodoptera litura (Lepidoptera: Noctuidae). Ann. Entomol. Soc. Am. 2000, 93, 1131-1137. [CrossRef]

11. Desneux, N.; Wajnberg, E.; Fauvergue, X.; Privet, S.; Kaiser, L. Oviposition behaviour and patch-time allocation in two aphid parasitoids exposed to deltamethrin residues. Entomol. Exp. Appl. 2004, 112, $227-235$. [CrossRef]

12. Chen, X.; Ma, K.; Li, F.; Liang, P.; Liu, Y.; Guo, T.; Song, D.; Desneux, N.; Gao, X. Sublethal and transgenerational effects of sulfoxaflor on the biological traits of the cotton aphid, Aphis gossypii Glover (Hemiptera: Aphididae). Ecotoxicology 2016, 25, 1841-1848. [CrossRef] [PubMed]

13. Guo, L.; Desneux, N.; Sonoda, S.; Liang, P.; Han, P.; Gao, X.W. Sublethal and transgenerational effects of chlorantraniliprole on biological traits of the diamondback moth, Plutella xylostella L. Crop. Prot. 2013, 48, 29-34. [CrossRef]

14. Costa, M.A.; Moscardini, V.F.; Da Costa Gontijo, P.; Carvalho, G.A.; De Oliveira, R.L.; De Oliveira, H.N. Sublethal and transgenerational effects of insecticides in developing Trichogramma galloi (Hymenoptera: Trichogrammatidae). Ecotoxicology 2014, 23, 1399-1408. [CrossRef] [PubMed] 
15. Tan, Y.; Biondi, A.; Desneux, N.; Gao, X.W. Assessment of physiological sublethal effects of imidacloprid on the mirid bug Apolygus lucorum (Meyer-Dü r). Ecotoxicology 2012, 21, 1989-1997. [CrossRef] [PubMed]

16. Pan, H.; Liu, Y.; Liu, B.; Lu, Y.; Xu, X.; Qian, X.; Wu, K.; Desneux, N. Lethal and sublethal effects of cycloxaprid, a novel cis-nitromethylene neonicotinoid insecticide, on the mirid bug Apolygus lucorum. J. Pest Sci. 2014, 87, 731-738. [CrossRef]

17. Chi, H.; You, M.; Atlıhan, R.; Smith, C.L.; Kavousi, A.; Özgökçe, M.S.; Güncan, A.; Tuan, S.J.; Fu, J.W.; Xu, Y.Y.; et al. Age-Stage, two-sex life table: An introduction to theory, data analysis, and application. Entomol. Gen. 2020, 103-124. [CrossRef]

18. Feng, Y.; Zhang, A. A floral fragrance methyl benzoate is an efficient green pesticide. Sci. Rep. 2017, 7, 1-9. [CrossRef]

19. Choudhary, M.I.; Naheed, N.; Abbaskhan, A.; Musharraf, S.G.; Siddiqui, H.; Atta-ur-Rahman. Phenolic and other constituents of fresh water fern Salvinia molesta. Phytochemistry 2008, 69, 1018-1023. [CrossRef]

20. Atkinson, R. A structure-activity relationship for the estimation of rate constants for the gas-phase reactions of $\mathrm{OH}$ radicals with organic compounds. Int. J. Chem. Kinet. 1987, 19, 799-828. [CrossRef]

21. Mostafiz, M.M.; Jhan, P.K.; Shim, J.K.; Lee, K.Y. Methyl benzoate exhibits insecticidal and repellent activities against Bemisia tabaci (Gennadius) (Hemiptera: Aleyrodidae). PLoS ONE 2018, 13, e0208552. [CrossRef]

22. Mostafiz, M.M.; Hassan, E.; Shim, J.K.; Lee, K.Y. Insecticidal efficacy of three benzoate derivatives against Aphis gossypii and its predator Chrysoperla carnea. Ecotoxicol. Environ. Saf. 2019, 184, 109653. [CrossRef] [PubMed]

23. Mostafiz, M.M.; Shim, J.K.; Hwang, H.S.; Bunch, H.; Lee, K.Y. Acaricidal effects of methyl benzoate against Tetranychus urticae Koch (Acari: Tetranychidae) on common crop plants. Pest Manag. Sci. 2020, 76, 2347-2354. [CrossRef] [PubMed]

24. Mostafiz, M.M.; Hassan, E.; Shim, J.K.; Lee, K.Y. Lethal and sublethal effects of methyl benzoate on the predatory bug Nesidiocoris tenuis. Insects 2020, 11, 377. [CrossRef] [PubMed]

25. Wang, J.J.; Cheng, W.X.; Ding, W.; Zhao, Z.M. The effect of the insecticide dichlorvos on esterase activity extracted from the psocids, Liposcelis bostrychophila and L. entomophila. J. Insect Sci. 2004, 4, 23. [CrossRef] [PubMed]

26. Weill, M.; Fort, P.; Berthomieu, A.; Dubois, M.P.; Pasteur, N.; Raymond, M. A novel acetylcholinesterase gene in mosquitoes codes for the insecticide target and is non-homologous to the ace gene Drosophila. Proc. R. Soc. Lond. Ser. B Biol. Sci. 2002, 269, 2007-2016. [CrossRef]

27. Booth, L.H.; Wratten, S.D.; Kehrli, P. Effects of reduced rates of two insecticides on enzyme activity and mortality of an aphid and its lacewing predator. J. Econ. Entomol. 2007, 100, 11-19. [CrossRef]

28. Bradford, M.M. A rapid and sensitive method for the quantitation of microgram quantities of protein utilizing the principle of protein-dye binding. Anal. Biochem. 1976, 72, 248-254. [CrossRef]

29. Ellman, G.L.; Courtney, K.D.; Andres, V.; Featherstone, R.M. A new and rapid colorimetric determination of acetylcholinesterase activity. Biochem. Pharmacol. 1961, 7, 88-95. [CrossRef]

30. Harel, M.; Kryger, G.; Rosenberry, T.L.; Mallender, W.D.; Lewis, T.; Fletcher, R.J.; Guss, J.M.; Silman, I.; Sussman, J.L. Three-dimensional structures of Drosophila melanogaster acetylcholinesterase and of its complexes with two potent inhibitors. Protein Sci. 2000, 9, 1063-1072. [CrossRef]

31. Chi, H.; Liu, H. Two new methods for the study of insect population ecology. Bull. Inst. Zool. Acad. Sin. 1985, 24, 225-240.

32. Chi, H. Life-table analysis incorporating both sexes and variable development rates among individuals. Environ. Entomol. 1988, 17, 26-34. [CrossRef]

33. Chi, H.; Su, H.Y. Age-stage, Two-sex life tables of Aphidius gifuensis (Ashmead) (Hymenoptera: Braconidae) and its host Myzus persicae (Sulzer) (Homoptera: Aphididae) with mathematical proof of the relationship between female fecundity and the net reproductive rate. Environ. Entomol. 2006, 35, 10-21. [CrossRef]

34. Huang, Y.B.; Chi, H. Life tables of Bactrocera cucurbitae (Diptera: Tephritidae): With an invalidation of the jackknife technique. J. Appl. Entomol. 2013, 137, 327-339. [CrossRef]

35. Chi, H. TWOSEX-MSChart: A Computer Program for the Age-Stage, Two Sex Life Table Analysis; National Chung Hsing University: Taichung, Taiwan, 2019.

36. Efron, B.; Tibshirani, R. An Introduction to the Bootstrap; Chapman and Hall/CRC: London, UK, $1994 ;$ p. 436. 
37. Huang, H.W.; Chi, H.; Smith, C.L. Linking demography and consumption of Henosepilachna vigintioctopunctata (Coleoptera: Coccinellidae) fed on Solanum photeinocarpum (Solanales: Solanaceae): With a new method to project the uncertainty of population growth and consumption. J. Econ. Entomol. 2018, 111, 1-9. [CrossRef] [PubMed]

38. SAS Institute Inc. Base SAS 9.4 Procedures Guide, Statistical Procedures, 2nd ed.; SAS Institute Inc.: Cary, NC, USA, 2013.

39. SigmaPlot version 12.5. Systat Software, Inc., San Jose, California, USA. Available online: http://www. sigmaplot.co.uk/products/sigmaplot/sigmaplot-details.php (accessed on 2 September 2020).

40. Gowthaman, U.; Jayakanthan, M.; Sundar, D. Molecular docking studies of dithionitrobenzoic acid and its related compounds to protein disulfide isomerase: Computational screening of inhibitors to HIV-1 entry. BMC Bioinform. 2008, 9, S14. [CrossRef]

41. Hevener, K.E.; Zhao, W.; Ball, D.M.; Babaoglu, K.; Qi, J.; White, S.W.; Lee, R.E. Validation of molecular docking programs for virtual screening against dihydropteroate synthase. J. Chem. Inf. Model. 2009, 49, 444-460. [CrossRef]

42. Dayan, F.E.; Cantrell, C.L.; Duke, S.O. Natural products in crop protection. Bioorganic Med. Chem. 2009, 17, 4022-4034. [CrossRef]

43. Rajashekar, Y.; Tonsing, N.; Shantibala, T.; Manjunath, J.R. 2, 3-Dimethylmaleic anhydride (3, 4-Dimethyl-2, 5-furandione): A plant derived insecticidal molecule from Colocasia esculenta var. esculenta (L.) Schott. Sci. Rep. 2016, 6, 1-7. [CrossRef]

44. Feng, Y.; Chen, J.; Zhang, A. Commercially available natural benzyl esters and their synthetic analogs exhibit different toxicities against insect pests. Sci. Rep. 2018, 8, 1-9. [CrossRef]

45. Ullah, F.; Gul, H.; Yousaf, H.K.; Xiu, W.; Qian, D.; Gao, X.; Tariq, K.; Han, P.; Desneux, N.; Song, D. Impact of low lethal concentrations of buprofezin on biological traits and expression profile of chitin synthase 1 gene (CHS1) in melon aphid, Aphis gossypii. Sci. Rep. 2019, 9, 1-13. [CrossRef]

46. Yuan, H.B.; Li, J.H.; Liu, Y.Q.; Cui, L.; Lu, Y.H.; Xu, X.Y.; Li, Z.; Wu, K.M.; Desneux, N. Lethal, sublethal and transgenerational effects of the novel chiral neonicotinoid pesticide cycloxaprid on demographic and behavioral traits of Aphis gossypii (Hemiptera: Aphididae). Insect Sci. 2017, 24, 743-752. [CrossRef] [PubMed]

47. He, Y.; Zhao, J.; Wu, D.; Wyckhuys, K.A.G.; Wu, K. Sublethal effects of imidacloprid on Bemisia tabaci (Hemiptera: Aleyrodidae) under laboratory conditions. J. Econ. Entomol. 2011, 104, 833-838. [CrossRef] [PubMed]

48. Rix, R.R.; Ayyanath, M.M.; Christopher Cutler, G. Sublethal concentrations of imidacloprid increase reproduction, alter expression of detoxification genes, and prime Myzus persicae for subsequent stress. J. Pest Sci. 2016, 89, 581-589. [CrossRef]

49. Sial, M.U.; Zhao, Z.; Zhang, L.; Zhang, Y.; Mao, L.; Jiang, H. Evaluation of insecticides induced hormesis on the demographic parameters of Myzus persicae and expression changes of metabolic resistance detoxification genes. Sci. Rep. 2018, 8, 1-8. [CrossRef] [PubMed]

50. Ayyanath, M.M.; Cutler, G.C.; Scott-Dupree, C.D.; Sibley, P.K. Transgenerational shifts in reproduction hormesis in green peach aphid exposed to low concentrations of imidacloprid. PLoS ONE 2013, 8, e74532. [CrossRef] [PubMed]

51. Cordeiro, E.M.G.; de Moura, I.L.T.; Fadini, M.A.M.; Guedes, R.N.C. Beyond selectivity: Are behavioral avoidance and hormesis likely causes of pyrethroid-induced outbreaks of the southern red mite Oligonychus ilicis? Chemosphere 2013, 93, 1111-1116. [CrossRef]

52. Zuo, Y.; Wang, K.; Lin, F.; Li, Y.; Peng, X.; Piñero, J.C.; Chen, M. Sublethal effects of indoxacarb and beta-cypermethrin on Rhopalosiphum padi (Hemiptera: Aphididae) under laboratory conditions. Florida Entomol. 2016, 99, 445-450. [CrossRef]

53. Ali, E.; Liao, X.; Yang, P.; Mao, K.; Zhang, X.; Shakeel, M.; Salim, A.M.A.; Wan, H.; Li, J. Sublethal effects of buprofezin on development and reproduction in the white-backed planthopper, Sogatella furcifera (Hemiptera: Delphacidae). Sci. Rep. 2017, 7, 1-9. [CrossRef]

54. Xu, L.; Zhao, C.Q.; Zhang, Y.N.; Liu, Y.; Gu, Z.Y. Lethal and sublethal effects of sulfoxaflor on the small brown planthopper Laodelphax striatellus. J. Asia. Pac. Entomol. 2016, 19, 683-689. [CrossRef]

55. Yousaf, H.K.; Shan, T.; Chen, X.; Ma, K.; Shi, X.; Desneux, N.; Biondi, A.; Gao, X. Impact of the secondary plant metabolite cucurbitacin B on the demographical traits of the melon aphid, Aphis gossypii. Sci. Rep. 2018, 8, 1-10. [CrossRef] 
56. Nathan, P.W.; Sears, T.A. Action of methyl hydroxybenzoate on nervous conduction. Nature 1961, 192, 668-669. [CrossRef] [PubMed]

57. Opdyke, D.L.J. (Ed.) Monographs on Fragrance Raw Materials; Pergamon Press: New York, NY, USA, 1979; p. 537.

58. Senthil Nathan, S.; Young Choi, M.; Yul Seo, H.; Hoon Paik, C.; Kalaivani, K.; Duk Kim, J. Effect of azadirachtin on acetylcholinesterase (AChE) activity and histology of the brown planthopper Nilaparvata lugens (Stål). Ecotoxicol. Environ. Saf. 2008, 70, 244-250. [CrossRef] [PubMed]

(C) 2020 by the authors. Licensee MDPI, Basel, Switzerland. This article is an open access article distributed under the terms and conditions of the Creative Commons Attribution (CC BY) license (http://creativecommons.org/licenses/by/4.0/). 